\title{
UMA VISÃO CONSTRUCIONAL DA ORDEM VERBO-SUJEITO COMO ESTRATÉGIA DE FOCALIZAÇÃO NO PORTUGUÊS DO BRASIL
}

\author{
CONSTRUCTIONAL APPROACH OF SUBJECT-VERB ORDER AS A FOCUSING \\ STRATEGY IN BRAZILIAN PORTUGUESE
}

\author{
Roberto de Freitas Junior ${ }^{1}$ \\ Priscilla Mouta Marques ${ }^{2}$
}

\section{RESUMO:}

No presente trabalho, apresentamos os primeiros resultados de uma pesquisa em curso que visa a mapear a configuração sincrônica de parte da rede construcional de focalização no Português do Brasil (PB). Dessa forma, a partir dos pressupostos teórico-metodológicos da Linguística Funcional Centrada no Uso (LFCU), buscamos descrever as características formais e funcionais de construções ativas e passivas licenciadas pelo esquema $[(\mathrm{X}) \mathrm{VSN}]_{\mathrm{FOC}}$ e representadas, respectivamente, pelos pareamentos $[(\mathrm{X}) \mathrm{VSN}]_{\mathrm{ATV}}$ e $\left.\left[(\mathrm{X}) \mathrm{V}_{\mathrm{AUX}} \mathrm{V}_{\mathrm{PP}} \mathrm{SN}\right]\right]_{\text {PAS. }}$ Embora em relação aos elementos constituintes ambas as construções se assemelhem, no que tange à focalização, as construções ativas se diferiram das passivas em relação à porção oracional sobre a qual recaiu o caráter [+Focal].

PALAVRAS-CHAVE: Linguística Funcional Centrada no Uso; Gramática de Construções; rede construcional; ordem VS; focalização.

\begin{abstract}
:
In the present work, we present the first results of an ongoing research that aims to map the synchronous configuration of part of the focus construction network in Brazilian Portuguese. Thus, from the theoretical-methodological assumptions of Usage-based Functional Linguistics (LFCU), we seek to describe the formal and functional characteristics of active and passive constructions licensed by the schema $[(\mathrm{X}) \mathrm{VSN}]_{\mathrm{FOC}}$, and represented, respectively, by the pairings $[(\mathrm{X}) \mathrm{VSN}]_{\mathrm{ATV}}$ and $[(\mathrm{X})$ $\left.\left.\mathrm{V}_{\mathrm{AUX}} \mathrm{V}_{\mathrm{PP}} \mathrm{SN}\right]\right]_{\mathrm{PAS}}$. Although these constructions present similarities on form, concerning focalization they differ from each other: active constructions tend to present the NP focused, instead of the role sentence as we could attest most frequently in passive ones.
\end{abstract}

KEYWORDS: Usage-based Functional Linguistics; Construction Grammar; construction network; VS order; focusing.

\footnotetext{
${ }^{1}$ Universidade Federal do Rio de Janeiro (UFRJ). Professor do Programa de Pós-Graduação em Linguística e do Departamento de Letras-LIBRAS. Contato: robertofrei@letras.ufrj.br.

${ }^{2}$ Universidade Federal do Rio de Janeiro (UFRJ). Professora do Programa de Pós-Graduação em Linguística e do Departamento de Linguística e Filologia. Contato: priscillamouta@letras.ufrj.br.
} 


\section{INTRODUÇÃO}

Neste artigo, buscamos apresentar os primeiros resultados de um estudo sincrônico acerca dos papeis formal e funcional do esquema $[(\mathrm{X}) \mathrm{VSN}]_{\mathrm{FOC}}$, que encabeça subesquemas que se referem às cláusulas ativas e passivas de sujeito posposto no Português do Brasil (PB). Brevemente, propomos a investigação da tradicionalmente chamada 'ordem VS' à luz dos pressupostos teórico-metodológicos da Linguística Funcional Centrada no Uso (LFCU), caracterizada como um amálgama entre os postulados da Linguística Funcional NorteAmericana e os fundamentos da Linguística Cognitiva especialmente no que tange aos princípios da Gramática das Construções (GC) (GOLDBERG, 1995 e 2006; CROFT, 2001).

Em outras palavras, conduzimos nossas análises buscando relacionar aspectos tanto do âmbito da forma quanto do âmbito do sentido/função do esquema supracitado, disponível na rede construcional do PB atual. Nesse sentido, buscamos uma ponte entre estudos anteriores sobre a ordem VS no PB e a abordagem construcional, partindo da ideia de que a língua é uma rede de pareamentos de forma-sentido (construções) interconectados entre si, que pode ser modificada pelo uso que os falantes fazem dela em situações reais de comunicação. Trata-se, portanto, de um esquema-modelo, que reúne o que é comum a um conjunto interligado de elementos de mesma natureza (GOLDBERG, 1995).

Posto isso, este artigo foi organizado da seguinte forma: inicialmente, apresentamos alguns resultados de estudos acerca da ordem do sujeito posposto no PB, como os de Naro e Votre (1999), MOUTA MARQUES (2012) e Furtado da Cunha (1989), que, dentre os diversos trabalhos sobre o tema, foram aqui destacados dadas as contribuições para o delineamento da pesquisa sobre a qual versa este texto. Entre tais contribuições, está, por exemplo, o fato, sugerido por alguns, de que sincronicamente o PB apresenta tendência de uso do chamado "sujeito posposto" restrito a contextos de construções monoargumentais. Tal fato estaria relacionado ao processo de enrijecimento da ordenação vocabular nessa língua, em favor da ordem SV(C). Esta observação ratifica a necessidade de uma investigação de natureza construcional para a questão: não estaria a cristalização de tal ordenação vocabular relacionada à construcionalização de um esquema, de papéis de forma e sentido próprios, que se fixa na rede construcional do PB? Em seguida, apresentamos o quadro teórico-metodológico adotado e a análise proposta, via discussão dos subesquemas destacados, [(X)VSN $]_{\mathrm{ATV}}$ e $\left.\left[(\mathrm{X}) \mathrm{V}_{\mathrm{AUX}} \mathrm{V}_{\mathrm{PP}} \mathrm{SN}\right]\right]_{\mathrm{PAS}}$. Por fim, explicitamos os resultados obtidos na pesquisa até o momento. 


\section{A ORDEM VERBO-SUJEITO NO PB}

O estudo de Naro e Votre (1999) representa uma das principais pesquisas sobre o uso do, assim chamado, sujeito posposto no PB. No conjunto de conclusões a que chegam os autores, destacamos duas características do fenômeno, que são importantes para o que será discutido neste artigo: (a) o caráter apresentacional de referentes novos da ordem VS e (b) a recorrência de elementos adverbiais à esquerda do verbo.

Em particular, a discussão sobre o caráter apresentacional de um referente, especialmente de um sintagma nominal ( $\mathrm{SN}$ ), revelou-se, nessa e em demais pesquisas, ponto de destaque. Pesquisas subsequentes à de Naro e Votre (1999), reconhecem a associação entre o caráter de introdução de informação nova da cláusula VS, mas dão destaque, entretanto, ao fato de o caráter apresentacional de $\mathrm{SN}$ não estar categoricamente relacionado ao fenômeno da posposição, como defende, por exemplo, Berlinck (1997).

Em seu estudo diacrônico sobre a posição do sujeito em relação ao verbo no PB, MOUTA MARQUES (2012) descreve as motivações de ocorrência do sujeito nas posições pré e pósverbais. A pesquisa revela que construções VS (verbo-sujeito) com verbos mais frequentes tenderam a permanecer mais tempo na língua e a se configurarem como contextos restritos de ocorrências no português atual, que teve sua organização sintática modificada em favor da ordem SV(C). Esta é uma informação particularmente importante para nosso trabalho, pois nos leva ao questionamento acerca da função desta construção no PB sincrônico, dada sua especialização, em termos de ordenação vocabular, em uma língua que se torna, canonicamente, $\mathrm{SV}(\mathrm{C})$

Outro estudo relevante para a atual pesquisa é o de Furtado da Cunha (1989), que traz contribuições importantes para o entendimento das construções passivas no PB. Em seu trabalho, a autora trata, dentre outros assuntos, das motivações discursivas para o uso da construção passiva analítica nas ordens SV e VS. Mostra que, com relação ao domínio de atribuição do elemento [+Tópico] na estrutura passiva do $\mathrm{PB}$, ao optar pela ordenação SV, o falante posicionaria o argumento paciente na posição de sujeito, caracterizando um papel de maior topicidade para este elemento. A pesquisa mostra, ainda, sobre o uso da construção passiva na ordem VS, que tal motivação discursiva não se aplica. Segundo a autora, as passivas VS não apresentam um enunciado que remete a um tópico. No contexto de passividade de ordem VS, o que teríamos seria justamente a quebra da estrutura informacional tópicocomentário, que estaria, por sua vez, relacionada à quebra da ordenação vocabular SV. A 
estrutura VS passiva passaria, então, a funcionar como um "bloco de informação" composto também pelo sujeito-paciente em posição de [Foco].

Assim, as motivações discursivas que determinariam a quebra da relação tópicocomentário não estariam resumidas apenas à necessidade de destopicalização do SN agente da oração transitiva prototípica, mas também à própria destopicalização do referente paciente, posto não ser ele, também, o ponto de partida para o desencadeamento da informação. Em outras palavras, esta seria uma estratégia de refocalização do elemento paciente, ora focalizado, na oração transitiva original correspondente.

Outra contribuição importante do estudo de Naro e Votre (1999) supracitado consiste na observação acerca da recorrência de Sintagmas Adverbiais à esquerda do item verbal dessa oração. Novamente, a observação acerca do papel de elementos adverbiais à esquerda da cláusula VS servirá de insumo para a pesquisa aqui apresentada, na medida em que defendemos seu papel como parte da estrutura argumental da construção $[(\mathrm{X}) \mathrm{VSN}]_{\mathrm{FOC}}$, aqui investigada.

O ponto central que reúne os estudos brevemente aqui listados é que se, por um lado, a estrutura informacional é um fator fortemente relacionado à ordenação vocabular verbo-sujeito, por outro, o que parece estar em cena não seria exatamente a emergência de SNs novos no discurso. Nesse sentido, a questão do status informacional do referente parece se tratar muito mais de um epifenômeno, relacionado a um fato gramatical: a existência de um esquema, de papel funcional relacionado à focalização, disponível na rede de construções linguísticas do PB.

\section{A CONSTRUÇÃO [(X)VSN]FOC}

Em termos gerais, nosso trabalho, conforme anteriormente mencionado, tem por objetivo a análise sincrônica de padrões construcionais relacionados ao esquema $[(\mathrm{X}) \mathrm{VSN}]_{\mathrm{FOC}}$ no $\mathrm{PB}$, uma construção de natureza esquemática e complexa com papel funcional e sentido bem definidos na mente dos falantes do PB. Vejamos alguns dados instanciados pelo esquema em investigação, na voz ativa e na voz passiva ${ }^{3}$ :

I. Voz ativa:

(1)“Acabou a farra dos Concursos Culturais, nova portaria altera o seu uso" (Corpus do Português).

II. Voz passiva:

\footnotetext{
${ }^{3}$ Dados retirados dos corpora utilizados nessa pesquisa: O Corpus do Português e o Jornal O Globo
} 
(2)“Nos pedidos com 20 itens, foram indicados os números dos documentos” (Jornal “O Globo").

Em nosso estudo, buscamos, especificamente, verificar as características formais dos subesquemas instanciados pelo esquema em questão e investigar a questão da informatividade - em particular, a do papel de foco informacional -, para a explicação de suas características no nível da função/sentido. Tendo por base estudos linguísticos que relacionam o uso do sujeito posposto ao status informacional de maior novidade de seu referente, o presente trabalho defende que esta construção sintática esteja muito mais relacionada à estratégia de perspectivização de um evento ou de um referente do que simplesmente relacionada à introdução de informações novas no nível do discurso.

Assim, propomos a pergunta: é possível pensarmos na existência do esquema $[(\mathrm{X}) \mathrm{VSN}]_{\mathrm{FOC}}$ na rede construcional do esquema de focalização do $\mathrm{PB}$, tendo em vista o enrijecimento de sua ordenação vocabular (SVC)? E, nesse caso, é possível pensarmos em termos de esquema, subesquema e microconstruções, levando em conta aspectos relacionados à esquematicidade de tal construção (TRAUGOTT \& TROUSDALE, 2013)?

A proposta de Traugott e Trousdale (2013) apresenta um olhar para a rede construcional que incluiria, no caso do objeto aqui pesquisado, um conjunto amplo de outras possíveis construções focalizadoras do PB, que poderiam apresentar características de forma bem independentes. Esse conjunto de construções estaria sob o mesmo domínio funcional. Este, por sua vez, se subdividiria em conjuntos de esquemas a ele relacionados mais em termos de sentido/função do que de forma.

Por seu turno, os subesquemas aqui tratados, $[(\mathrm{X}) \mathrm{VSN}]$ ATV e $\left[(\mathrm{X}) \mathrm{V}_{\mathrm{AUX}} \mathrm{V}_{\mathrm{PP} S \mathrm{SN}}\right]$ pas, que instanciam cláusulas VS ativas e passivas, encabeçariam outros subesquemas que, em termos de sentido, poderiam indicar tendência de focalização ou do todo sentencial, por perspectivização do evento oracional, ou do SN em posição pós-verbal, fato que poderia estar relacionado a fatores como a informatividade, a extensão e a definitude deste referente. Tomando por base a literatura acerca da ordem VS no PB (Naro e Votre (1999), Berlinck (1989), Duarte (1993), MOUTA MARQUES (2012), Furtado da Cunha (1989) e Spanó (2002; 2008)), alguns pontos aparecem como recorrentes a respeito do assunto, em particular, quanto ao papel apresentacional desta oração e do status informacional dos SNs em questão.

Confrontando as conclusões de tais estudos, chegamos à conclusão que generalizações absolutas quanto ao caráter apresentacional da cláusula VS, assim como ao do caráter categórico de [+novo] de seu referente não correspondem aos achados das referidas pesquisas. 
Por outro lado, o conjunto de informações dali gerado parece sugerir uma particularidade das orações VS do PB: elas tendem a se constituir como porções discursivas que trazem algum grau apresentacional, ou mesmo de reintrodução de informação, o que pode indicar, independentemente de questões relacionadas ao caráter de novidade da informação, a proeminência, o destaque, uma perspectivização diferenciada desta informação. Nesse sentido, o que parece estar compartilhado, no nível funcional, pelas orações VS do PB, ativas e passivas, está muito mais em conformidade com o conceito de FOCO informacional.

Assim, amplia-se o olhar sobre as cláusulas VS, trazendo à baila a discussão sobre o fenômeno de focalização (LAMBRECHT, 1994). Muito além da introdução ou reintrodução de referentes no discurso, as cláusulas VS, ativas e passivas, serviriam muito mais como estratégias de perspectivização de eventos (foco sentencial), de referentes (foco argumental) ou de informação nova em relação a algo pressuposto (foco via tópico-comentário). Tais estratégias de perspectivização refletiriam a função pragmática da construção, por sua vez, estocada na rede construcional, ou seja, na própria gramática, do falante do PB.

Em suma, no nível da forma, $[(\mathrm{X}) \mathrm{VSN}]_{\mathrm{FOC}}$ seria uma construção de natureza monoargumental, cujos subsquemas principais, ativo e passivo, podem apresentar um elemento $\mathrm{X}$, à esquerda do verbo, e que, no nível do sentido, apresentaria papel relacionado à focalização ou do SN, ou do conjunto oracional. Observemos os dados abaixo:

(3) “... apareceu uma mancha vermelha no meu olho esquerdo na parte branca, eu fui pentear o cabelo e meu olho coçou e quando olhei o espelho tinha uma mancha vermelha na parte branca" (Corpus do Português).

(4) "Em dezembro de 2013, foram apresentados pedidos para a liberação (...)" (Jornal "O Globo")

Os constructos (3) e (4), de diferentes maneiras, exemplificam as motivações de nossa proposta de investigação construcional da ordem VS. Em (3) temos, na verdade, duas instâncias de SNs pospostos ao verbo. Nas duas ocorrências, verificamos a existência de verbos inacusativos. Resumidamente, tratam-se de orações monoargumentais cujo argumento detém papel temático [- agente] e que pode não receber marcação de caso nominativo. Tais características colocam o exemplo no cerne das características da inacusatividade.

De fato, apoiados nos estudos anteriores sobre a ordem VS já citados, verificamos que é o contexto da inacusatividade o mais propício à ocorrência de orações VS. Nesse sentido, reforçamos a ideia de que os dados referidos em (3) possam se constituir de uma mesma 
construção, de um mesmo pareamento esquemático de forma e função: se por um lado, no nível formal, tratam-se de orações monoargumentais cujos SNs emergem na posição à direita do verbo, no nível funcional, revelam a tendência de que o SN seja dotado de menor caráter de agentividade e de tópico, o que reforça nossa hipótese de que tal constituinte detenha maior caráter de focalização, devido a sua posição pós-verbal, papel apresentacional de um referente ou mesmo de um evento, no caso, 'o fato de algo surgir no corpo do sujeito', além do objeto em si, 'a mancha vermelha'.

Por outro lado, em (4), verificamos outra instância de inacusatividade, não lexical, mas estrutural: a oração passiva apresenta estrutura monoargumental, único SN de baixo caráter de agentividade e que não necessariamente receberá Caso Nominativo para sua interpretação de papel temático. Ainda, note-se o caráter de novidade e consequente saliência discursiva do SN 'pedidos para liberação'. A oração dialoga com contexto maior, na medida em que apresenta um encaminhamento para possível resolução criminal, até então desenvolvida na matéria. O caráter introdutório exercido pela oração passiva novamente traz à tona a possibilidade de interpretação do papel de focalização da oração em questão, via quebra do fluxo informacional até ali encaminhado. Assim, reforça-se a ideia de que se tratam ambas orações, ativa e passiva, de instâncias de um mesmo esquema, já que tanto no nível da forma, quanto no do sentido/função, compartilham de características comuns.

Abaixo resumimos as informações especificadas na representação acima apresentada:

- $\mathrm{X}=$ elementos adverbiais ou outros, que desempenham, possivelmente, papel coesivo anafórico, refletindo a própria estrutura informativa canônica Tópico-Comentário;

- $\mathrm{V}=$ uma construção verbal — um verbo ou uma locução verbal — representada como construção de menor grau de transitividade, segundo a escala de Hopper e Thompson (1980);

- $\mathrm{SN}=$ um SN pleno, possivelmente [-Agentivo], [+Extenso], [-Definido], [-Dado] e $[+$ Focal $]$.

No nível da função, investigamos, como dito, de que forma tal construção estaria relacionada a alguma estratégia de focalização. Para tal, seguimos os pressupostos de Lambrecht (1994), que define três grandes estruturas de focalização:

(a) a tradicional divisão tópico-comentário, em que há distribuição diferenciada de informação mais ou menos pressuposta no nível do discurso, sendo a parte menos pressuposta, o foco, o próprio predicado sintático; 
(b) a estrutura de foco sentencial, em que o conjunto da informação apresentada tende a ser menos pressuposto e

(c) a estrutura de foco argumental, em que a focalização recai sobre um elemento identificado como o de maior grau de novidade no nível discursivo.

Nesse sentido, o esquema $[(\mathrm{X}) \mathrm{VSN}]_{\text {FOC }}$ estaria sempre relacionado a algum dos esquemas de focalização apresentados acima. Esteja, ou não, o elemento X presente no construto, seja o SN um elemento introduzido pela primeira vez no discurso, ou retomado após menção tardia, $[(\mathrm{X}) \mathrm{VSN}]_{\mathrm{FOC}}$ seria o esquema que abarca os subesquemas que instanciam as orações ativas e passivas VS do PB e que ora apresentariam função de foco total, ora função de foco parcial. Em outras palavras, ora apresentariam ou função focalizadora de tópico-comentário, de foco sentencial ou de foco argumental, como propomos na figura abaixo:

Figura 1: Esquemas de Perspectivização

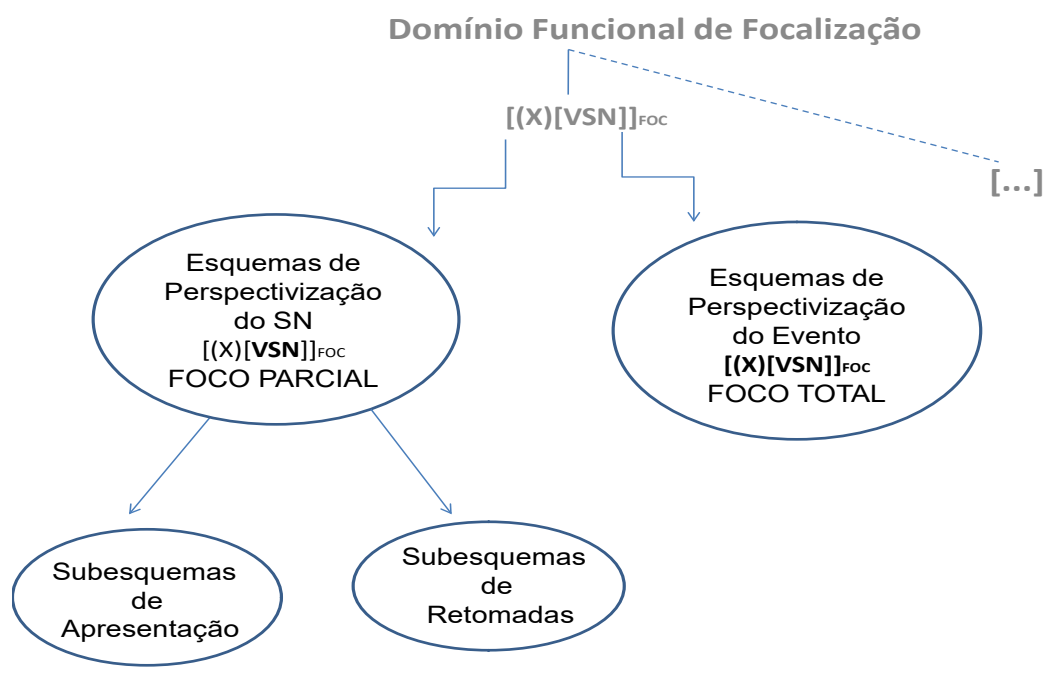

Tendo por base a divisão acima apresentada, uma proposta de representação hierárquica em rede, especificamente acerca do papel funcional e de sentido da construção [(X)VSN]FOC, seria: 
Figura 2: Esquemas de Focalização

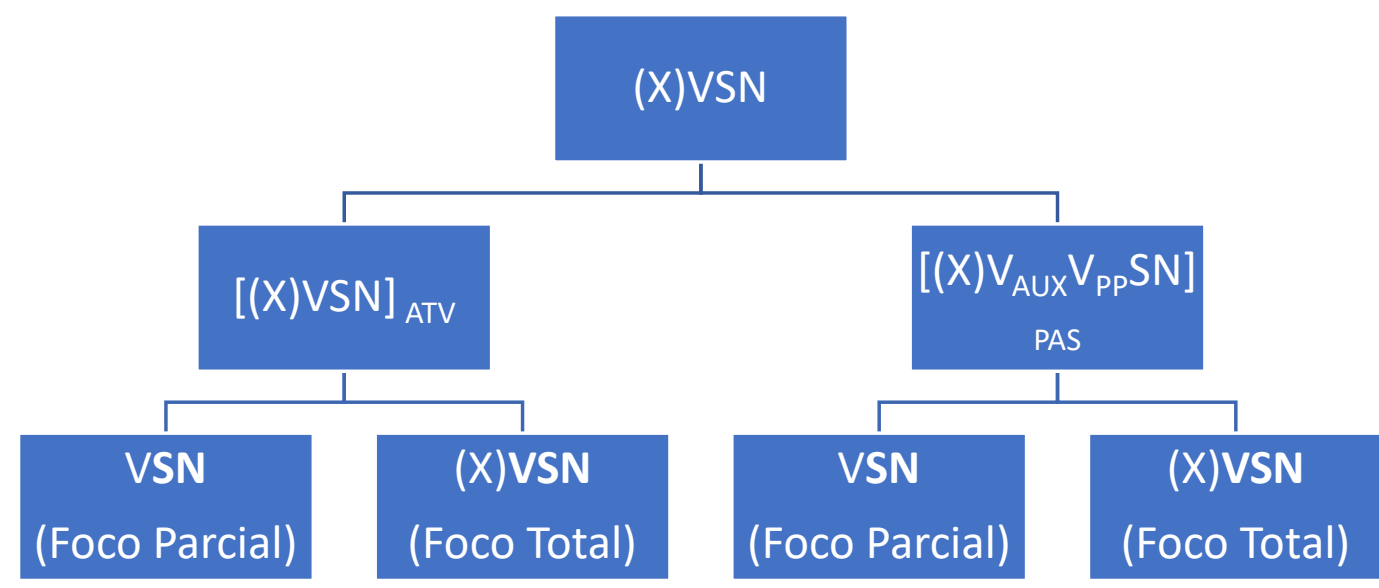

A rede em questão representa a possibilidade de focalização total da cláusula VSN, encabeçada ou não por um elemento [+Tópico], de papel coesivo no nível do discurso, e a possibilidade de focalização de referentes novos, cumprindo a função apresentativa, ou de retomada, também típica desse tipo de construção ${ }^{4}$.

Por estar em rede, apesar da associação inevitável entre inacusatividade, lexical ou estrutural, e a construção aqui tratada, podemos verificar, ainda, a presença de itens verbais ou nominais menos esperados nesse contexto, dada a força coercitiva (DIEWALD, 2010) da própria construção. Em outras palavras, verbos monoargumentais de natureza inergativa, ou mesmo SNs de maior caráter de agentividade, podem emergir nesse padrão construcional, seguindo, como previsto, sua orientação focalizadora, prevista no nível do sentido, apesar de se afastarem das características prototípicas dos constituintes dessa construção. O dado em (5) exemplifica o ponto apresentado. Apesar de ser constituído pelo verbo 'correr', prototipicamente inergativo e, portanto, mais fortemente associado a um SN [+agente], temos uma forte adequação do constructo aos papeis formais e funcionais da construção esquemática $[(\mathrm{X}) \mathrm{VSN}]_{\mathrm{FOC}}$. Note-se, particularmente, o caráter focalizado do referente 'uma noite inteira' e seu papel de novidade no nível do discurso.

(5) "Mande o João Bento buscar o Antônio Castro. João é bom de montaria e não se demorará. Entre o ir e o voltar, correu uma noite inteira”.

\footnotetext{
${ }^{4}$ Note-se que estão gravados em negrito os constituintes que estariam focalizados em cada uma das construções. 


\subsection{Apontamentos metodológicos}

Os dados desta pesquisa foram analisados segundo os fatores que hipoteticamente podem definir o caráter de focalização do construto, a saber: o status informacional do SN, última menção deste no nível do discurso, extensão, grau de definitude e emergência do SN, e papel coesivo do elemento X. Os fatores selecionados para a análise são, em parte, oriundos de pesquisas anteriores sobre a ordem VS em PB, tendo-se em conta, agora, novas perspectivas de análise, em função de podermos verificar o papel de focalização da construção. Assim, foram desenvolvidas análises quantitativas e qualitativas para o estudo, que visa, em suma, à verificação do tipo de escopo de foco em jogo: total ou parcial, no evento ou no referente.

Como a pesquisa visa investigar o papel do esquema abstrato $[(\mathrm{X}) \mathrm{VSN}]_{\mathrm{FOC}}$, a partir da análise de constructos, dados reais, de voz ativa e passiva no $\mathrm{PB}$, utilizamos dois corpora distintos. Assim, optamos por trabalhar com o Corpus do Português ${ }^{5}$, com relatos de casos de natureza mais informal, para a coleta de dados na voz ativa, e com o jornal $O$ Globo, com textos jornalísticos de orientação formal, para a coleta de cláusulas passivas. A possibilidade de trabalharmos com gêneros discursivos mais propícios ao surgimento dos dados orientou a escolha dos corpora, que serviram para a coleta de dados sincrônicos.

No que concerne à análise de dados na voz ativa, optamos por trabalhar com orações com os verbos acontecer e correr. Tínhamos por hipótese a possibilidade de que construtos com verbos acontecer e correr apresentassem comportamentos construcionais distintos, por se tratarem de dois itens lexicais monoargumentais de semântica bem diferente. Enquanto o primeiro, claramente, prevê um SN [- agentivo] em sua grade temática, o segundo prevê um elemento [+ agentivo]. Os resultados referentes ao papel de focalização das orações VS, de itens verbais de diferentes características semânticas, poderiam ser diferenciados e, assim, poderíamos mesmo caracterizar a ocorrência de outra construção, de sentido também diferenciado. Por outro lado, como o sentido da construção independe do significado dos itens de suas partes, mesmo estes sendo de naturezas diferentes, o papel de focalização poderia se manter em muitos dos casos.

Quanto ao fator Extensão do SN, optamos pela contagem de até 10 sílabas para sintagmas [extensos]. A partir desse número, teríamos um $\mathrm{SN}$ de maior massa fônica, uma característica comum de informações de maior grau de novidade e, portanto, focalizadas.

Para a análise do status Informacional do $\mathrm{SN}$, optamos por trabalhar com duas macrocategorias (dado e novo), já que não vimos maior necessidade de refinamento de análise

\footnotetext{
${ }^{5} \mathrm{https}$ ://corpus.byu.edu/cdp/x.asp
} 
com número maior de variáveis de informatividade, visto que, tanto paras as construções ativas quanto para as passivas, não tivemos, ainda, um número de dados que assim o exigisse.

No total, foram analisadas 50 ocorrências de VS passiva, 31 ocorrências com o verbo acontecer e 35 com o verbo correr. Iniciamos a descrição da pesquisa tratando da investigação da construção ativa.

\subsection{Resultados iniciais}

Apresentamos, na sequência, uma breve discussão sobre os resultados já alcançados nesta investigação.

\subsubsection{Resultados relacionados à construção ativa}

$\mathrm{O}$ estudo sobre o funcionamento da construção $[(\mathrm{X}) \mathrm{VSN}]_{\mathrm{ATV}}$ tem como base alguns parâmetros de transitividade propostos por Hopper e Thompson (1980). Nesta perspectiva, o conceito de transitividade considera não apenas o item verbal, mas características concernentes ao conjunto de participantes que compõem a oração. Ao considerarmos os construtos originados a partir do padrão $[(\mathrm{X}) \mathrm{VSN}]_{\mathrm{ATV}}$, estaríamos lidando com um grupo de construções que apresentam os mais baixos índices de transferência, dado seu único participante argumental e a sua natureza semântica de baixa agentividade.

Em um continuum, construções com o verbo acontecer constituiriam um grupo de construções monoargumentais com escala mínima de transitividade, fato relacionado aos traços semânticos [-cinese] do verbo e [-agentividade/volição] do SN. Por outro lado, construções com o verbo correr formariam um grupo de construções monoargumentais posicionadas em um nível acima na escala de transitividade, fato relacionado aos traços semânticos [+cinese] e [+agentividade/volição].

\subsubsection{Resultados referentes a construtos com verbo acontecer}

Na Tabela 1, vemos que 90,3\% dos SN das orações com o verbo acontecer apresentaram maior grau de novidade: 
Tabela 1: Extensão, definitude e estatuto informacional do $\mathrm{SN}$ em $[(\mathrm{X}) \mathrm{VSN}]_{\mathrm{ATV}}-$ verbo acontecer

\begin{tabular}{|c|c|c|c|c|c|}
\hline \multicolumn{2}{|c|}{} & \multicolumn{2}{|c|}{ DEFINITUDE } & \multicolumn{2}{c|}{$\begin{array}{c}\text { ESTATUTO } \\
\text { INFORMACIONAL }\end{array}$} \\
\hline$[+$ EXT $]$ & {$[-E X T]$} & {$[+$ DEF $]$} & {$[-D E F]$} & NOVO & DADO \\
\hline $68 \%$ & $32 \%$ & $45,2 \%$ & $54,8 \%$ & $90,3 \%$ & $9,7 \%$ \\
$(34 / 31)$ & $(16 / 31)$ & $(14 / 31)$ & $(17 / 31)$ & $(28 / 31)$ & $(3 / 31)$ \\
\hline
\end{tabular}

Associado ao status informacional de maior novidade do SN está o grau de definitude e extensão desse elemento. Vemos que $54,8 \%$ dos dados analisados apresentaram menor grau de definitude, o que sugere maior grau de novidade da informação no nível do discurso. Ainda, 68\% dos dados foram considerados extensos: uma característica comum de informações mais focalizadas, na medida em que a maior quantidade de massa fônica aponta para maior proeminência informativa. Tais características confirmam, novamente, o caráter funcional de focalização da construção.

Como podemos ver nos resultados da Tabela 2, a construção $[(\mathrm{X}) \mathrm{VSN}]_{\mathrm{ATV}}$, com uso do verbo acontecer, emergiu mais associada à função de focalização do evento, com $61,3 \%$ dos dados, do que à de focalização do $\mathrm{SN}$, com 38,7\%.

Tabela 2 - Focalização em $[(\mathrm{X}) \mathrm{VSN}]_{\mathrm{ATV}}$ - verbo acontecer

\begin{tabular}{|c|c|}
\hline REFERENTE & EVENTO \\
\hline $38,7 \%$ & $61,3 \%$ \\
$(12 / 31)$ & $(19 / 31)$ \\
\hline
\end{tabular}

Também observamos, na análise da voz ativa, a tendência de elementos de natureza adverbial à esquerda da locução verbal, ou seja, no slot $(\mathrm{X})$, e a de itens que podem figurar neste slot apresentar caráter coesivo, de ordem anafórica, como vemos na Tabela 3: 
Tabela 3: Preenchimento do slot $(\mathrm{X})$ em $[(\mathrm{X}) \mathrm{VSN}]_{\mathrm{ATV}}$ - verbo acontecer

\begin{tabular}{|c|c|c|c|}
\hline \multirow{2}{*}{ ADVERBIAL } & $\begin{array}{c}\text { CONJUNÇÃO } \\
\text { ADVERBIAL }\end{array}$ & $\begin{array}{c}\text { ORAÇÃO } \\
\text { REDUZIDA }\end{array}$ & OUTROS \\
\hline $51,7 \%$ & $20,7 \%$ & $13,8 \%$ & $13,8 \%$ \\
$(15 / 29)$ & $(6 / 29)$ & $(4 / 29)$ & $(4 / 29)$ \\
\hline
\end{tabular}

A análise dos dados revelou que a presença de adverbiais, seja um SPrep, um SAdv ou mesmo uma conjunção adverbial, está diretamente relacionada a alguma função coesiva exercida por tal elemento. A entrada do adverbial tende a estabelecer alguma ligação entre porções discursivas anteriores à emergência da cláusula $[(\mathrm{X}) \mathrm{VSN}]_{\mathrm{ATV}}$, favorecendo seu papel focalizador da informação introduzida: o evento ou seu referente. O dado (6), abaixo, exemplifica esta questão:

(6) "O Marlon Brando estava fazendo um filme em Paris, em 1957, com o Dean Martin,

o The Young Lions (Os Deuses Vencidos), e eu estava lá. Quis demais conhecê-lo. No

mesmo dia, aliás, aconteceu uma história incrível” (Corpus do Português).

O exemplo (7) representa uma ocorrência clássica do subesquema $[(\mathrm{X}) \mathrm{VSN}]_{\text {ATV }}$ exercendo papel de foco sentencial, ou focalização de evento. As características semânticas de seu referente, [- definido], [- animado] e [- volitivo] apontam, como podemos ver, para o papel focal do SN. Entretanto, tendo-se em conta seu conjunto discursivo, vemos que toda a oração emerge com forte grau de novidade no nível do discurso, o que reforça a ideia de perspectivização de evento. Vale notar, ainda, o papel do adverbial à esquerda do verbo, o que reforça a hipótese de foco sentencial, via estrutura tópico-comentário.

(7) "No LP seguinte, que foi "Miragem", que também saíram alguns compactos desse LP.

Na época aconteceu uma coisa engraçada - A Polygram queria me levar pra lá, tinha um produtor na CBS que não largava do meu pé, achava que era meu dono".

Entendemos, assim, que a presença, quase sempre de natureza adverbial e de caráter coesivo, à esquerda do verbo desencadeia a estrutura informacional canônica de tópicocomentário, posicionando a informação do comentário, a própria cláusula VS, na posição de informação focalizada, fato ainda reforçado pela natureza de maior novidade da informação veiculada $(90,3 \%)$. Como visto, tal possibilidade de focalização é prevista em Lambrecht (1994) e parece estar diretamente relacionada ao esquema $[(\mathrm{X}) \mathrm{VSN}]_{\mathrm{ATV}}$ no PB sincrônico. 


\subsubsection{Resultados referentes a construtos com verbo correr}

Como previsto, as investigações iniciais sobre os construtos $[(\mathrm{X}) \mathrm{VSN}]_{\mathrm{ATV}}$ com o verbo correr revelaram caráter diferenciado em relação àqueles com acontecer. Este fato deve estar relacionado às diferenças dos traços de transitividade (HOPPER \& THOMPSON, 1980) entre esses dois verbos.

Se, por um lado, detectamos comportamento regular dos construtos em relação aos pressupostos de forma/sentido da construção, por outro, detectamos que isto ocorre mais em situações em que a construção não apresenta maior caráter de idiomatização. Em outras palavras, verificamos que há um continuum que vai de um subesquema [+esquemático] a outro [-esquemático], mais idiomatizado, hierarquicamente, mais ou menos próximos da construção prototípica, como vemos na representação abaixo:

Figura 3: Tipos de Correr

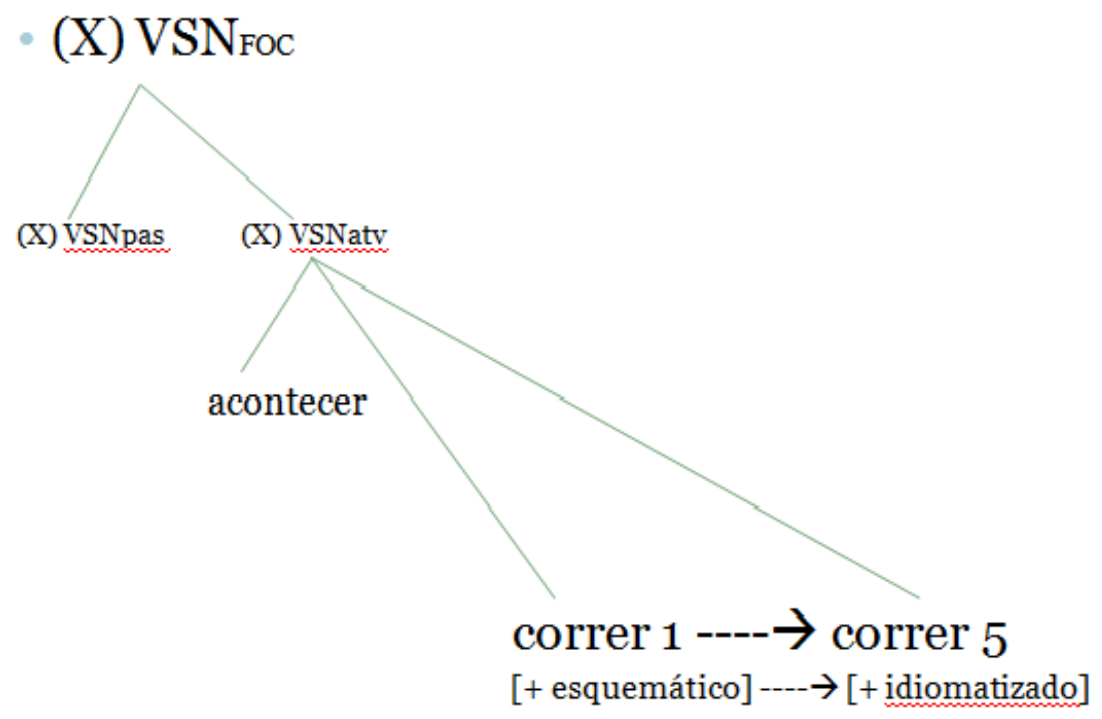

$\mathrm{Na}$ análise dos dados com o verbo correr, foram detectados diferentes types construcionais, que foram organizados a partir de uma proposta taxonômica. A análise qualitativa dos dados nos fez perceber que, quanto menor o grau de idiomaticidade da construção, maior sua associação ao esquema $[(\mathrm{X}) \mathrm{VSN}]_{\mathrm{ATV}}$. O que percebemos é que, quando há maior idiomaticidade, a focalização do evento discursivo parece acontecer de modo mais categórico.

Desta forma, a partir da análise dos dados, detectamos 5 comportamentos construcionais que definem as possibilidades de sentido do verbo da construção $[(\mathrm{X}) \mathrm{VSN}]_{\mathrm{ATV}}$ com o verbo 
'correr': Deslocamento fisico [+ animado], Deslocamento físico [- animado], Deslocamento metafórico de sensação, Deslocamento notícia e Deslocamento metafórico de tempo.

A taxonomia Deslocamento físico [+ animado] indica, em um extremo de esquematicidade, que a ação correr possui sentido de movimento para frente de um SN agentivo. A taxonomia Deslocamento metafórico de tempo, em outro polo, aponta para um maior grau de idiomaticidade, já que seu SN é necessariamente uma informação de tempo. Tal fato pode sugerir a existência de um outro subesquema, que instancia construtos do tipo 'correu um tempo', 'correu uma noite' etc.

Assim, a Tabela 3 é baseada nos papéis de sentido e grau de esquematicidade dos subesquemas do item correr e relaciona cada um aos status informacionais de seus SNs:

Tabela 3 - Types construcionais e estatuto informacional do SN em $[(\mathrm{X}) \mathrm{VSN}]_{\mathrm{ATV}}$ - verbo correr

\begin{tabular}{|c|c|c|c|}
\hline CORRER & DADO & NOVO & TOTAL \\
\hline $\begin{array}{c}\text { Deslocamento físico } \\
\text { [+ animado] }\end{array}$ & 1 & 6 & 7 \\
\hline $\begin{array}{c}\text { Deslocamento físico } \\
{[- \text { animado }]}\end{array}$ & 1 & 3 & 6 \\
\hline $\begin{array}{c}\text { Deslocamento } \\
\text { metafórico de } \\
\text { sensação }\end{array}$ & 0 & 6 & 9 \\
\hline $\begin{array}{c}\text { Deslocamento } \\
\text { notícia }\end{array}$ & 0 & 9 & 9 \\
\hline $\begin{array}{c}\text { Deslocamento } \\
\text { metafórico de tempo }\end{array}$ & 0 & 9 & 35 \\
\hline TOTAL & 2 & 33 & $(100 \%)$ \\
\hline
\end{tabular}

Os números sugerem que 94,3\% dos SNs apresentaram natureza de maior novidade. Entretanto, o fato de termos SNs [+novos] não garante a função de focalização do SN. A análise qualitativa dos dados nos permitiu verificar que tanto nas orações [+ esquemáticas], quanto nas [- esquemáticas], a focalização total de evento pareceu ser mais evidente. 
$\mathrm{Na}$ Tabela 4, vemos que a construção $[(\mathrm{X}) \mathrm{VSN}]_{\mathrm{ATV}}$ com verbo correr parece estar mais associada à função de focalização de evento do que à de focalização de SN. Em 57,1\% dos dados analisados, foi esta a tendência observada:

Tabela 4 - Focalização em $[(\mathrm{X}) \mathrm{VSN}]_{\mathrm{ATV}}$ - verbo correr

\begin{tabular}{|c|c|}
\hline SINTAGMA NOMINAL & EVENTO \\
\hline $42,9 \%$ & $57,1 \%$ \\
$(15 / 35)$ & $(20 / 35)$ \\
\hline
\end{tabular}

Parece relevante o fato de tal comportamento também ter sido observado nos resultados referentes ao verbo acontecer. Assim, se o esquema $[(\mathrm{X}) \mathrm{VSN}]_{\mathrm{ATV}}$ encabeça, hierarquicamente, por um lado, um subesquema de focalização de evento e outro de referente, por outro, ele parece cumprir no PB, mais frequentemente, papel gramatical de focalização de evento veiculado.

Os dados (8) e (9), na sequência, evidenciam tal tendência. Note-se que independentemente de possíveis restrições semânticas impostas pelo verbo, por se tratar de informações não prontamente disponíveis no discurso precedente, os referentes em questão tornam-se fortes candidatos a aparecerem na posição prototípica de foco, pós-verbal:

(8) "Nem princesa verdadeira concorreria em beleza, em riqueza e elegância. Sofia chorou, de fato, e os irmãos aplaudiram. Correu a negrada toda assuntando a aparição - aparição, sim, senhora, imagem celestial, há muito não existia uma noiva tão perfeita".

(9) 'Parecia, dos joelhos p' ra baixo, tudo sumido, quando não rabo de peixe que mal encostava no chão. E logo se sentiu um pitiu tão forte que até dava vontade de vomitar.

Correu um tremor no fio do lombo do João e da Merandolina. Tiveram um susto de bater queixo. - Minha coroa do Divino! É boto, disse o mariscador pondo-se em pé".

O construto em (8) evidencia a possibilidade de uma construção monoargumental com SN [-novo], [+definido], [+animado] e [+volitivo], embalado na posição à direita do verbo, espaço prototípico de focalização, a despeito das restrições semânticas prototípicas do verbo 'correr'. Nesse sentido, percebemos a prevalência do sentido construcional, a despeito de possíveis restrições semânticas relacionadas ao item verbal em questão. Apesar da forte associação de determinados itens verbais a certas construções, o sentido construcional definirá novas possibilidade de usos, via inserções de itens menos prototípicos. 
A tendência de focalização total parece ter sido a preferida, graças ao papel das construções de maior grau de idiomaticidade e ao papel do elemento $\mathrm{X}$ anafórico, constatado na maior parte dos casos verificados. A presença de elementos de natureza adverbial à esquerda da locução verbal que apresentam caráter coesivo de ordem anafórica pôde ser observada em 20 dos 35 dados de verbo correr atestados e apresentaram as seguintes características, como vemos na Tabela 5:

Tabela 5: Preenchimento do slot $(\mathrm{X})$ em $[(\mathrm{X}) \mathrm{VSN}]_{\mathrm{ATV}}$ - verbo correr

\begin{tabular}{|c|c|c|}
\hline ADVERBIAL & CONJUNÇÃO ADVERBIAL & OUTROS \\
\hline $15 \%$ & $45 \%$ & $40 \%$ \\
$(3 / 20)$ & $(9 / 20)$ & $(8 / 20)$ \\
\hline
\end{tabular}

A título de exemplificação, o exemplo (10) abaixo, representa o grupo de construções $[(\mathrm{X}) \mathrm{VSN}]_{\mathrm{ATV}}$ com verbo 'correr' com a presença de adverbiais à esquerda:

(10) Depois correram notícias de que há na Clareira mais armas do que no quartel do Exército em Belém.

O uso do adverbial 'depois' em (10) exemplifica o papel coesivo do elemento $\mathrm{X}$ na construção $[(\mathrm{X}) \mathrm{VSN}]_{\mathrm{ATV}}$, ao estabelecer. com a contexto anterior, uma ligação de sentido e continuidade garantida pela oração VS subsequente.

\subsubsection{Resultados relacionados à construção passiva}

Na Tabela 6, apresentamos a análise referente ao SN de 50 dados até então investigados. Essa abordagem inicial nos permitiu observar a tendência, já esperada, de maior extensão, menor grau de definitude e maior grau de novidade do SN observado:

Tabela 6: Extensão, definitude e estatuto informacional do $\mathrm{SN}$ em $\left[(\mathrm{X}) \mathrm{V}_{\mathrm{AUX}} \mathrm{V}_{\mathrm{PP}} \mathrm{SN}\right]_{\mathrm{PAS}}$

\begin{tabular}{|c|c|c|c|c|c|}
\hline \multicolumn{2}{|c|}{} & \multicolumn{2}{|c|}{ DEFINITUDE } & \multicolumn{2}{c|}{$\begin{array}{c}\text { ESTATUTO } \\
\text { INFORMACIONAL }\end{array}$} \\
\hline$[+$ EXT $]$ & {$[-\mathrm{EXT}]$} & {$[+\mathrm{DEF}]$} & {$[-\mathrm{DEF}]$} & NOVO & DADO \\
\hline $68 \%$ & $32 \%$ & $74 \%$ & $26 \%$ & $86 \%$ & $14 \%$ \\
$(34 / 50)$ & $(16 / 50)$ & $(37 / 50)$ & $(13 / 50)$ & $(43 / 50)$ & $(7 / 50)$ \\
\hline
\end{tabular}


Tais características ratificam, de imediato, a análise qualitativa acerca do papel de focalização da construção, mostrando, entretanto, que, no contexto de voz passiva, ela parece estar mais relacionada à focalização do $\mathrm{SN}$ e não necessariamente do evento, como retratamos na Tabela 7, abaixo:

Tabela 7 - Focalização em $\left[(\mathrm{X}) \mathrm{V}_{\mathrm{AUX}} \mathrm{V}_{\mathrm{PP}} \mathrm{SN}\right]_{\mathrm{PAS}}$

\begin{tabular}{|c|c|}
\hline REFERENTE & EVENTO \\
\hline $64 \%$ & $36 \%$ \\
$(32 / 50)$ & $(18 / 50)$ \\
\hline
\end{tabular}

As características relacionadas ao status informacional do $\mathrm{SN}$ e sua extensão denotam a expressividade da informação do SN em questão. Diferentemente dos construtos instanciados pelo subesquema das orações ativas, em que o item verbal poderia fazer parte do conjunto de informação com maior grau de proeminência e expressividade, nos construtos gerados pelo subesquema de orações passivas, em muitos casos, a locução verbal não detinha maior grau de novidade informacional. Desta forma, o caráter de novidade e consequente focalização do SN parece se destacar nas cláusulas passivas, constituindo-se uma diferença entre os subsquemas $[(\mathrm{X}) \mathrm{VSN}]_{\mathrm{ATV}}$ e $\left[(\mathrm{X}) \mathrm{V}_{\mathrm{AUX}} \mathrm{V}_{\mathrm{PP}} \mathrm{SN}\right]_{\mathrm{PAS}}$.

Há de se levar em conta, ainda, que muitos SNs das cláusulas passivas são SNs que, após emergirem no discurso, são retomados após certo distanciamento da menção anterior. Assim, verificamos uma estratégia de refocalização deste $\mathrm{SN}$, que, embora detenha menor grau de novidade, por um lado, carrega maior grau de expressividade ao surgir novamente no discurso, desta vez não em posição prototípica de tópico. Por emergir na posição pós-verbal, a perspectivização deste SN é diferenciada, tornando-o mais focalizado.

Também observamos a tendência de surgimento de elementos de natureza adverbial à esquerda da locução verbal, ou seja, no slot $(\mathrm{X})$, tal como mostrado na Tabela 8:

Tabela 8: Preenchimento do slot $(\mathrm{X})$ em $\left[(\mathrm{X}) \mathrm{V}_{\mathrm{AUX}} \mathrm{V}_{\mathrm{PP}} \mathrm{SN}\right]_{\mathrm{PAS}}$

\begin{tabular}{|c|c|c|}
\hline ADVERBIAL & $\begin{array}{c}\text { CONJUNÇÃO } \\
\text { ADVERBIAL }\end{array}$ & PRONOME RELATIVO \\
\hline $85,7 \%$ & $8,6 \%$ & $5,7 \%$ \\
$(30 / 35)$ & $(3 / 35)$ & $(2 / 35)$ \\
\hline
\end{tabular}


A análise dos dados revela que em mais de $90 \%$ dos 35 construtos encabeçados por (X) tivemos um elemento de natureza adverbial. Desse total todos os elementos à esquerda do verbo apresentaram caráter coesivo, de ordem anafórica, como evidenciado no dado (11), abaixo:

(11) Na sua decisão, Moro justificou o mandado como medida para preservação da ordem pública, citando o tumulto ocorrido no último dia 17, em Barra Funda (SP), quando manifestantes pró e contra Lula se envolveram em confronto. Na ocasião, estava previsto um depoimento do ex-presidente em outro processo na Justiça paulista, que foi cancelado em cima da hora. (O Globo, 05/06/2016)

O SAdv em (11), 'Na ocasião' estabelece a ligação e continuidade textual, via retomada da informação temporal, entre a oração VS e a anterior. Esta se mostrou uma relação comum nos trechos em que identificamos as orações de sujeito posposto. Tal fato permite ainda, como dito, uma associação, em escala maior, entre a construção $[(\mathrm{X}) \mathrm{VSN}]_{\mathrm{FOC}}$ e estrutura tópicocomentário, mantendo o equilíbrio default da força informacional. A Tabela 9 trata de modo mais específico do caráter coesivo de elemento $\mathrm{X}$ identificado nas orações passivas:

Tabela 9 - Função textual de $(\mathrm{X})$ / [+Anafórica $]$ em $\left[(\mathrm{X}) \mathrm{V}_{\mathrm{AUX}} \mathrm{V}_{\mathrm{PP}} \mathrm{SN}\right]_{\mathrm{PAS}}$

\begin{tabular}{|c|c|c|}
\hline RETOMADA & $\begin{array}{c}\text { RETOMADA E } \\
\text { CONTINUIDADE }\end{array}$ & CONTINUIDADE \\
\hline $58 \%$ & $25 \%$ & $17 \%$ \\
$(7 / 12)$ & $(3 / 12)$ & $(2 / 12)$ \\
\hline
\end{tabular}

Vemos, na Tabela 4, que 83\% dos elementos na posição (X) apresentaram algum papel anafórico, funcionando via retomada de informação previamente mencionada e, às vezes, dando continuidade ao fluxo de informação.

As orações abaixo, retiradas do corpus para investigação das orações passivas, representam o grupo de construções $\left[(\mathrm{X}) \mathrm{V}_{\mathrm{AUX}} \mathrm{V}_{\mathrm{PP}} \mathrm{SN}\right]_{\mathrm{PAS}}$ :

(11) "Na ocasião, estava previsto um depoimento do ex-presidente em outro processo na Justiça paulista, que foi cancelado em cima da hora".

(12) "Nos pedidos com 20 itens, foram indicados os números dos documentos".

Nos exemplos acima, constatamos a presença do adverbial de papel coesivo à esquerda da locução verbal, além da (re)introdução de informações de maior grau de novidade no nível do discurso. Tais construtos parecem evidenciar a relação tópico-comentário, como visto, uma 
das possibilidades de organização discursiva relacionada ao papel de focalização da construção $[(\mathrm{X}) \mathrm{VSN}]_{\mathrm{FOC}}$. Note-se, ainda, o caráter de maior extensão e indefinitude do SN em (11) e a estratégia de retomada de SN (dado) em (12), que desloca o constituinte em questão de uma posição prototípica de tópico, à esquerda do verbo, para a posição prototípica de focalização. Há de se notar, ainda, que a possível retirada do elemento adverbial inicial, pontaria para a estrutura informacional de foco argumental, típica de focalização exclusiva de referente.

\section{CONSIDERAÇÕES FINAIS}

Diante dos resultados aqui apresentados, torna-se possível pensarmos nas respostas às perguntas elaboradas no início deste artigo: é possível pensar na existência de uma construção monoargumental de SN pós-verbal, parte do esquema de focalização no Português do Brasil? E, nesse caso, podemos falar na existência de subesquemas e microconstruções relacionados à construção $[(\mathrm{X}) \mathrm{VSN}]_{\mathrm{FOC}}$ ?

A observação dos resultados nos permite concluir que as construções ativas e passivas VS aqui descritas partilham entre si, em termos de forma, grande semelhança em relação aos seus constituintes.

No campo do sentido, ambas as construções apresentaram papel focalizador. Entretanto, as construções ativas diferiram das passivas em relação à porção oracional sobre a qual se depositou o caráter [+Focal]. As construções ativas, tanto com o item verbal acontecer quanto com o correr, mostraram-se responsáveis, em maior grau, pela perspectivização do evento, isto é, a focalização de toda a cláusula. Por outro lado, as construções passivas tiveram maior índice de perspectivização de apenas um constituinte, ou seja, somente do SN, sobre o qual recaiu a focalização.

Essa diferença discursiva, porém, não constitui justificativa para considerarmos as construções ativas e passivas associadas a esquemas distintos. Ao contrário, em uma perspectiva construcional, entendemos que tais elementos apareçam relacionados a um mesmo esquema, um protótipo, que pode abarcar tanto construções que envolvem a perspectivização de SNs quanto construções que envolvem a perspectivização de eventos. 


\section{REFERÊNCIAS}

BERLINCK, R. (1989). A construção VS no Português do Brasil: uma visão diacrônica do fenômeno da ordem. In: Tarallo, F. (org.) Fotografias sociolinguísticas. Campinas: Pontes.

. (1997).Nem tudo que é posposto é novo: estatuto informacional do SN e posição do sujeito em português. Alfa - Revista de Linguística, Araraquara, v. 41, n. especial, p. 57-78.

CROFT, W. (2001). Radical Construction Grammar: Syntactic Theory in Typological Perspective. Oxford: Oxford University Press.

DIEWALD, G. (2006). Context types in grammaticalization as constructions. Constructions SV1-9/2006 (www.constructions-online.de, urn:nbn:de:0009-4-6860, ISSN 1860-2010) -

120.

DUARTE, M.E.L. (1993). Do pronome nulo ao pronome pleno: a trajetória do sujeito no português do Brasil. In: ROBERTS, I.; KATO, M.A. (Eds.) Português Brasileiro: uma viagem diacrônica. Campinas: Editora da UNICAMP. p.107-128.

FURTADO DA CUNHA, M. A. (1989). A passiva no discurso. Tese de doutorado. UFRJ: Rio de Janeiro.

GOLDBERG, A. (1995). Constructions: A construction grammar approach to argument structure. Chicago: University of Chicago Press.

. (2006). Constructions at work: the nature of generalization in language. Oxford:

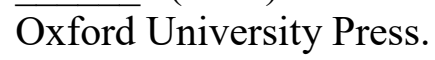

HOPPER, P.; THOMPSON, S. (1980) Transitivity in grammar and discourse. Language 56 (2): 251-299.

LAMBRECHT, K. (1994). Information structure and sentence form, Cambridge: Cambridge University Press.

MOUTA MARQUES, P. (2012). Estudo Diacrônico da Ordenação do Sujeito em Relação ao Verbo no Português. Tese de Doutorado. Rio de Janeiro: Universidade Federal do Rio de Janeiro.

NARO, A.; VOTRE, S. (1999) Discourse motivations for linguistic regularities. Verb/subject order in spoken Brazilian Portuguese. Probus 11: 73-98.

TRAUGOTT, E. C.; TROUSDALE, G. G. (2013). Constructionalization and Constructional Change. Oxford University Press: Oxford.

SPANÓ, M. (2002). A ordem V SN em construções monoargumentais, na fala culta do Português Brasileiro e Europeu. Dissertação de Mestrado. UFRJ. Rio de Janeiro.

. (2008). A ordem Verbo-Sujeito no Português Brasileiro e Europeu: Um estudo sincrônico da escrita padrão. Tese de Doutorado. UFRJ. Rio de Janeiro. 